\section{A Community-Building Framework for Collaborative Research Coordination across the Education and Biology Research Disciplines}

\author{
Nancy Pelaez, ${ }^{\text {t* }}$ Trevor R. Anderson, ${ }^{\ddagger}$ Stephanie M. Gardner, ${ }^{\dagger}$ Yue Yin, ${ }^{\S}$ \\ Joel K. Abraham," Edward L. Bartlett, " Cara Gormally," Carol A. Hurney," \\ Tammy M. Long, ${ }^{\circledR}$ Dina L. Newman, ${ }^{* *}$ Karen Sirum, ${ }^{+\dagger}$ and Michael T. Stevens ${ }^{* *}$ \\ 'Department of Biological Sciences and "Divisions of Chemical Education and Biochemistry, \\ Department of Chemistry, Purdue University, West Lafayette, IN 47907; \$College of Education, \\ University of Illinois at Chicago, Chicago, IL 60607; "Department of Biological Science, California \\ State University, Fullerton, Fullerton, CA 92831; 'Department of Science, Technology, and \\ Mathematics, Gallaudet University, Washington, DC 20002; \#Center for Teaching and Learning, \\ Colby College, Waterville, ME 04901; ${ }^{\circledR D}$ Department of Plant Biology, Michigan State University, \\ East Lansing, MI 48824; ; Thomas H. Gosnell School of Life Sciences, Rochester Institute of \\ Technology, Rochester, NY 14623; "Department of Biological Sciences, Bowling Green State \\ University, Bowling Green, $\mathrm{OH} 43403$; 㧊Department of Biology, Utah Valley University, \\ Orem, UT 84058
}

\begin{abstract}
Since 2009, the U.S. National Science Foundation Directorate for Biological Sciences has funded Research Coordination Networks (RCN) aimed at collaborative efforts to improve participation, learning, and assessment in undergraduate biology education (UBE). RCNUBE projects focus on coordination and communication among scientists and educators who are fostering improved and innovative approaches to biology education. When faculty members collaborate with the overarching goal of advancing undergraduate biology education, there is a need to optimize collaboration between participants in order to deeply integrate the knowledge across disciplinary boundaries. In this essay we propose a novel guiding framework for bringing colleagues together to advance knowledge and its integration across disciplines, the "Five 'C's' of Collaboration: Commitment, Collegiality, Communication, Consensus, and Continuity." This guiding framework for professional network practice is informed by both relevant literature and empirical evidence from community-building experience within the RCN-UBE Advancing Competencies in Experimentation-Biology (ACE-Bio) Network. The framework is presented with practical examples to illustrate how it might be used to enhance collaboration between new and existing participants in the ACE-Bio Network as well as within other interdisciplinary networks.
\end{abstract}

Collaboration between colleagues is important for advancing many fields. Major research initiatives are increasingly calling on faculty members to collaborate across disciplines and institutions. In fact, studies confirm that effective networks have resulted in more scientific productivity (Baker, 2015). According to Leahey (2016), in a review conducted to understand the accelerating and transformative shift toward collaboration and to identify gaps in this literature, collaboration represents a huge shift in the way scientific work is conducted. However, there is a lack of consensus regarding explanatory models of relevant factors or mechanisms to prompt greater collaboration rates (Leahey, 2016). To address this gap, we explore here the community-building features of a Research Coordination Network (RCN) aimed at improving participation, learning, and assessment in the context of undergraduate biology
Jeff Schinske, Monitoring Editor

Submitted April 3, 2017; Revised January 2, 2018; Accepted January 9, 2018

CBE Life Sci Educ June 1, 2018 17:es2

DOI:10.1187/cbe.17-04-0060

*Address correspondence to: Nancy Pelaez (npelaez@purdue.edu).

(c) 2018 N. Pelaez et al. CBE-Life Sciences Education @ 2018 The American Society for Cell Biology. This article is distributed by The American Society for Cell Biology under license from the author(s). It is available to the public under an Attribution-Noncommercial-Share Alike 3.0 Unported Creative Commons License (http://creativecommons.org/licenses/ by-nc-sa/3.0).

"ASCB ${ }^{\oplus "}$ and "The American Society for Cell Biology ${ }^{\circledR "}$ are registered trademarks of The American Society for Cell Biology. 
education (UBE), which is a current focus of the U.S. National Science Foundation (NSF; Woodin et al., 2010, 2012; Vasaly et al., 2013; Diaz Eaton et al., 2016). A goal for this essay is to document how the authors, as members of the Advancing Competencies in Experimentation-Biology (ACE-Bio) Network (NSF RCN-UBE project \#1346567), brought together stakeholders with a framework we created to promote collaboration among scientists and educators to foster improvements to biology education. Even when instructors are in departments with heavy teaching loads that preclude faculty research programs, networks can play an important role to "help facilitate a 'community of practice' enabling institutions with limited resources to develop and refine existing practices" (National Academies of Sciences, Engineering, and Medicine, 2017, p. 40). In particular, we describe here specific examples of key principles for a productive network that includes education specialists and biologists from different biological disciplines. We also examine how the elements of our framework relate to two published reports on collaborations across disciplines focused on biology education. Bergman and Schooley (2003) reported on a collaboration between scientists of the Microscopy Society of America and educators at the Lawrence Hall of Science that resulted in an outreach program for Microscopic Explorations, a publication that has been popular with teachers for more than 15 years. Peffer and Renken (2016) reported on practical strategies for collaboration across discipline-based education research (DBER) and the learning sciences. By presenting a framework that aligns well with features in published reports and that is also based on our own practical experience and observations, we offer a tool that we believe can be implemented and studied in building other interdisciplinary networks. By helping others understand how they might promote the functioning of a network by optimizing collaboration, we aim to inspire conversations about how to judge and improve the quality of such networks and thereby contribute to the advancement of biology education and biology in general.

\section{CONTEXT AND A PROBLEM}

Experimentation in biology is a prime example of an activity valued by all members of the biology community. Student understanding of experimentation (i.e., the set of competencies, concepts, and skills associated with the planning, design, completion, and dissemination of experiments in biology) is universally recognized as a crucial part of training for all biology students and has been so for nearly a century (Woodhull 1918; Mason, 1952; Davidson, 1957; Sirum and Humburg, 2011; Gormally et al., 2012; Spell et al., 2014; Dasgupta et al., 2014; Pelaez et al., 2015). Before participating in our network or attending our first meeting, 18 biology professors of the Assessment of Competence in Experimental Design in Biology Network were surveyed. These biology instructors universally perceived a lack of instructional tools for teaching about experimentation in biology. All participants agreed that both undergraduate and graduate students need to know experimental research better and that, overall, students have insufficient knowledge about experimental design. Most believed that undergraduates' knowledge about experimentation in biology is insufficiently assessed. These results confirmed our anecdotal observation that biology students, especially undergraduate students, need training in experimentation. In addition, the majority of the participants agreed that it is unclear what the expected objectives are for students to learn about experimental design, including which critical experimental research concepts and skills are important and how they should be assessed. This highlights the importance of building a network for collaborators to define the expected competencies as well as assessment guidelines to better address the problem of insufficient training of students. Addressing the lack of training in experimentation is one example of the many challenges faced by science students, educators, research scientists, and educational institutions.

No single group is likely to produce solutions to all these educational challenges. One promising approach that we deployed in our current project was to harness the complementary expertise of DBER experts, research biologists, and other biology faculty who mainly self-identify as biology education specialists, including instructors and department administrators, to collaborate in forming a network aimed at improving student competence with biological experimentation. Some collaborators are satisfied with the multidisciplinary model, wherein individuals each make separate contributions from the perspectives of their own disciplines (Baker, 2015). Others aspire to delve more deeply to achieve interdisciplinary knowledge integration. We use the term "interdisciplinary" to mean that the team effort allows some individuals to integrate information, techniques, tools, and data to achieve a new and different understanding (Boix Mansilla and Duraisingh, 2007). In performing the ACE-Bio Network project, we gained understanding from the literature about multidisciplinary collaboration and interdisciplinary knowledge integration. We also gathered our own observations to guide collaborative processes for addressing the abovementioned challenges, which, in turn, informed our formulation of various guiding principles for collaboration and the creation of a useful guiding framework. Our guiding principles for collaboration across disciplinary boundaries are summarized in Table 1 as the "Five 'C's' of Collaboration." In addition, Figure 1 illustrates the overlapping, interdependent nature of the five principles that work in concert during network collaborations. In the following sections, we introduce each principle and use our personal experience as education specialists and research scientists of the ACE-Bio Network to illustrate and describe how such principles are applied in an integrated manner in our own project and could potentially inform other networks facing similar challenges. Note that the narratives under each principle often make reference to more than one principle. This is because it is not possible to entirely separate any one principle from the other five. However, by examining each principle in turn, we are able to relate each one to our own experience as well as to key features from reports on interdisciplinary collaborations. To promote a sound collaboration within a network, we propose that these five principles should be integrated and none should be neglected.

\section{COMMITMENT: COLLABORATIVE ENGAGEMENT AND COMMITMENT STEM FROM A SHARED PROBLEM THAT IS RECOGNIZED BY DIVERSE DISCIPLINARY EXPERTS}

In this essay, we define "commitment" (Table 1 and Figure 1) as an intention to perform actions to bring about an outcome that requires investment of effort over a period of time. To focus network activities, members from different disciplines and with different goals and needs commit to confronting a shared 
TABLE 1. ACE-Bio Network guiding principles for collaboration across disciplinary boundaries: the "Five 'C's' of Collaboration"

\begin{tabular}{|c|c|}
\hline Collaborative principle & Principle in action $^{\mathrm{a}}$ \\
\hline 1. Commitment & $\begin{array}{l}\text { Network members are committed to reaching a shared goal. All individual and group activities are goal oriented, } \\
\text { because the team has justified why the particular problem requires a team approach. Guidelines and rules are } \\
\text { agreed upon for tasks that focus on achievement of the shared goal. }\end{array}$ \\
\hline 2. Collegiality & $\begin{array}{l}\text { Network members establish and maintain an environment in which participants respect one another, e.g., they } \\
\text { identify the expertise and team composition needed to address the shared problem; participants contribute } \\
\text { according to their specific domain or expertise; roles are established, tasks identified, and plans executed; the } \\
\text { product is critiqued, not the people; participants focus on improving both the process and the product. }\end{array}$ \\
\hline 3. Communication & $\begin{array}{l}\text { Network members consider disciplinary diversity when they communicate through sharing of resources, ideas, } \\
\text { difficulties, challenges, mistakes, failures, and feedback with others. As participants share personal ideas from } \\
\text { their own experience, everyone listens carefully and asks for clarification; by delving deeply, the common areas } \\
\text { and differences are recognized to achieve deeper levels of disciplinary integration. All participants have an } \\
\text { opportunity to contribute ideas, but are encouraged to avoid jargon, select inclusive language, and carefully } \\
\text { define terms to address language barriers to knowledge integration. }\end{array}$ \\
\hline 4. Consensus & $\begin{array}{l}\text { Network members actively incorporate other ideas into their own work and are committed to collective and ethical } \\
\text { decision making and reaching consensus on the roles, tasks, and processes for addressing the shared problem. } \\
\text { Organizational trust is established by having participants consider the ethics of any action taken by community } \\
\text { members and the impact from ethical performance-how collective actions will affect the well-being of others. } \\
\text { Decisions and tasks are set in accordance with benefits to the career trajectory of each participant. }\end{array}$ \\
\hline 5. Continuity & $\begin{array}{l}\text { Network members contribute to a shared resource collection. Leaders foster processes necessary for interdisciplinary } \\
\text { work and ways for network members to learn from the experiences of others by supporting those who cite work } \\
\text { done by others but also by fostering leader-member exchanges and face-to-face or virtual team interactions and } \\
\text { outreach. Alignment of individual and team contributions is continuously evaluated with respect to the } \\
\text { network's shared goal. }\end{array}$ \\
\hline
\end{tabular}

${ }^{a}$ These descriptions of each collaborative principle were compiled by the authors.

problem. In their report on strategies for collaboration across DBER and learning sciences, Peffer and Renken (2016) report on the need to identify an addressable problem and to discuss

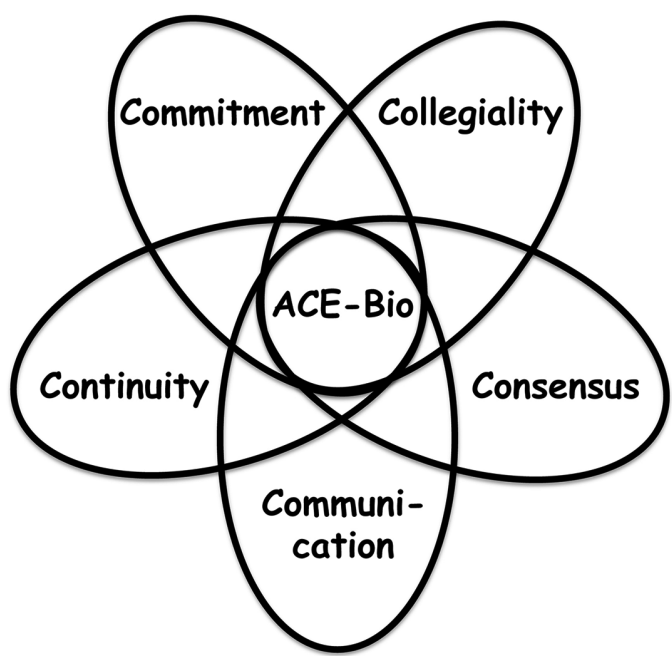

FIGURE 1. The "Five 'C's' of Collaboration for Research Coordination across Disciplinary Boundaries." This formulation of guiding principles for the ACE-Bio Network provided a useful framework for bringing together bench and field research scientists and education experts to focus on what students need to learn about biology experiments. Our framework is illustrated with a diagram showing overlap of five interdependent principles that we consider key to productive collaboration within our network and, therefore, that could potentially inform other networks. Although it was useful to identify and characterize each element, they were not independent but were used in concert during network activities, which are at the center of the figure. what they hope to accomplish together and why. The solving of undergraduate biology education problems might require a network of colleagues working across DBER and the learning sciences but may also need to include a range of suitably qualified biology faculty. For example, to solve a particular problem, the network might need to include faculty members who have an active research portfolio doing bench- or fieldwork in biology (the "research scientists") and faculty referred to as "science faculty with education specialties" (SFES), who focus on research in science education and/or K-12 or undergraduate science education (the "education specialists") (Bush et al., 2006, 2008, 2011, 2013, 2015).

Bench and field research scientists are essential members of such a network, because they engage undergraduate students in biology research and can convey their own experiences with biology as a research science to the students. However, research scientists typically have not received training in biology education and so they may be challenged to develop effective instruction and assessment methods on their own. In their report about collaborating educators and scientists in the Microscopy Society of America, Bergman and Schooley (2003) identified the need for a teacher's manual to expand and support the use of microscopes as a research tool in schools. The scientists had observed that their independently developed educational guidelines for microscopy were not popular among teachers. Their scientific skills and knowledge, therefore, would need to be complemented by that of the education specialists, so they turned to educators at the Lawrence Hall of Science to address their problem.

If improving students' experimental competence in biology is the goal, then networking within and between research scientists and education specialists could be a productive way to design innovative solutions. In a university biology department, 
individual faculty members might identify themselves somewhere along the range from research scientist to education specialist. This decision may be influenced by whether they are SFES who are still doing lab or field research or whether they are scientists with active research portfolios who are still considering their main focus to be on biology instruction. However, because not every college and university biology department has both education specialists and research scientists, a network across multiple sites is needed to synergistically unify people with the different types of expertise required to develop and disseminate the resources and assessments deemed necessary for addressing instructional problems shared by particular biologists.

\section{Research Scientists Define a Shared Problem They Commit to Addressing}

Many bench and field research scientists are tasked with training new researchers. Based on their experience, scientists have ideas about what constitutes competent experimentation, and those ideas are the starting point for actually identifying the elements of competence. Scientists in the ACE-Bio Network recognize that biology students are arriving unprepared or underprepared for thinking and working with the required concepts and skills of biological investigation. Recognizing this drives interest in new tools for teaching more effectively. However, there are physical and cultural boundaries that distinguish life science subdisciplines like ecology and cell biology. The diversity of research approaches could lead to a morass of specifics that are not necessarily generalizable. Furthermore, according to a National Academies report, the search for common features may generate concern about loss of their own disciplinary "identity," which is so "closely linked with the materials, techniques, instruments, and enabling theories of their research groups or laboratories" (Cooke and Hilton, 2015, p. 31).

\section{Faculty Who Are Education Specialists Commit to Collaborating with Research Scientists to Address the Shared Problem}

For biologists who are education specialists not engaged with bench or field research, it can be difficult to develop meaningful experiences for undergraduate students learning biology when the discipline is advancing so quickly. Science departments have struggled historically to develop courses that keep pace with changing technology and scientific advances (Del Giorno, 1969; American Association for the Advancement of Science [AAAS], 2011). Although disciplinary pace could be viewed as a barrier to creating meaningful educational experiences, others might argue it creates more affordances. In fact, the increased pace has diversified science research, so a broad array of options exist for engaging students in biology.

To maintain and grow a network of people from different life science subdisciplines who are geographically dispersed and have varied professional interests and constraints requires a single unifying goal to maintain member interest and commitment. Involving members as leaders in the ACE-Bio Network has helped to promote commitment and personal investment as well as some sense of distributed leadership. For example, various education specialists and scientists worked collaboratively with deep commitment in organizing and editing a list of basic competencies of biological experimentation after the first ACE-Bio Network meeting, and some also worked on follow-up surveys and consulted with other biology faculty members to help refine the document (Pelaez et al., 2017). Most who participated in the follow-up activities continued to attend future meetings and stayed involved. Those who did not do the work in between meetings may not have been as deeply committed, or if they did not volunteer for a work assignment, they may have slipped away unintentionally. Thus, an easy takeaway message is to give people concrete things to do that can inspire commitment to a task. Furthermore, we found that people were so motivated at conferences and meetings that they were tempted to take on more than can realistically be done. For this reason, the needs of the network were outlined and firm dates were set for completion of tasks to dampen that overenthusiasm, so that people might make informed decisions about their commitments. Participants appreciate knowing what is expected, when it is due, and in what format. But distributing the work also brings the challenge of maintaining a commitment to the focus of the network.

When bringing together experts with differing disciplinary perspectives on the shared problem, it is important to foster communication to come to a shared commitment to addressing the problem. Creative people do tangential thinking, so they naturally bring up topics beyond the intended focus. Tangential thinking introduces the risk of leading the project astray. To allow for creativity, we found it useful to define goals for each meeting, with facilitators assigned to lead people to focus on their commitment to a shared problem. One example relates to a meeting goal to examine the influence of context as students learn about experimentation in biology. Participants examined several contrasting cases: a biochemistry professor has students meet with a pancreatic cancer patient before the students investigate polyphenol molecules from the pomegranate to find out whether pomegranate promotes pancreatic cancer patient survival by inhibiting cancer cell invasion. Another professor takes groups of students at a 2-year college to Arabia Mountain in Georgia to explore microbial diversity by DNA isolation and sequencing to learn about research in the area of molecular biology (Jacob, 2012). The impact on student motivation with these compelling societal contexts at times derailed discussion away from the central problem, which was to focus on assessing how well these students were learning about experimentation. A facilitator reminded people to focus on evidence of learning about experimentation to bring commitment back to the deeper focus issue. By bringing people back on task, the facilitator helped participants in the ACE-Bio Network work to understand the conditions and contexts in which students struggle and succeed with various aspects of experimentation across the biology subdisciplines.

In summary, through applying the principle of commitment to collaborations within our ACE-Bio Network, we are establishing relationships that involve mutual dedication and the commitment to collaboratively address a shared problem that cannot be solved except by combining multiple perspectives. In our view, this is a principle that could be usefully applied to collaboratively addressing other challenges within other networks. 


\section{COLLEGIALITY: PRACTICALITIES OF FORGING INCLUSIVE RELATIONSHIPS}

Collegiality (Table 1 and Figure 1) is more than a relationship between colleagues. Collegiality unites individuals who trust and respect one another and work toward a common purpose. Collegiality relies on independence of thought, mutual respect, and people who treat one another equally and fairly to build inclusive relationships. For a successful collaboration, network members must establish and maintain a sense of collegiality so that they get to know, respect, and trust one another enough to work well together in sharing knowledge and ideas (Table 1). The multiple disciplines that engage with biology education at an institution where subdisciplines may be fractionated may find biological experimentation to be a good rallying point to bring different factions together in a collegial and fruitful interaction. In agreement with Cheruvelil et al. (2014), we found that having more than a single individual from a discipline ensures a "critical mass" for effective flow of ideas, because even within a discipline, individual team members have different points of view. However, people tend to associate with likeminded colleagues, so there is a need to continually, carefully, and strategically balance disciplines so that no stakeholder is missing. Collegiality also requires sensitivity and respect for cultural, racial, and gender differences, as reported by Cheruvelil et al. (2014), who also note the philosophical differences related to different ways investigators operate, including differences in research methodologies and in the amount and kinds of evidence deemed sufficient to generate new knowledge. Thus, each group of stakeholders may have unique perspectives, tools, and approaches to address the shared goal and different visions of how success in this area might look.

The collaboration reported by Bergman and Schooley (2003) was successful because the scientist and educator partners were ready to listen to and learn from one another in a collegial relationship. Likewise, in their report on practical strategies for collaboration across DBER and the learning sciences, Peffer and Renken (2016) emphasize the need to form collegial relationships by seeking to understand through dialogue the areas of overlap and convergence as well as important distinctions between the disciplines. Now in its third year, the ACE-Bio Network has directly addressed these challenges using the same collegial approach with the following strategies for integrating input from more than 40 educators and researchers in biology and biology education.

\section{Gather a Range of Experts to Tackle the Problem with a Collegial Process}

The approach taken by the ACE-Bio Network was informed by the adult learning and faculty development literature (Wlodkowski, 1999; Anderson and Rogan, 2011; Rogan and Anderson, 2011; Anderson et al., 2011; Felder et al., 2011; D'Avanzo et al., 2012). Invitations were purposefully extended to recruit a range of biology and biology education instructors and researchers, faculty development specialists, and academics from different types of institutions and at different career stages. Being explicit about the membership of the network, that each member has expertise and something to contribute that is not identical to what others bring and that each perspective is equally important, helps promote collegiality. This was not just implied, but was an explicit goal for group work. Being transparent about why different stakeholders are present and valued in the network helps create collegiality. Such sampling of different stakeholders interacting in a collegial and fruitful manner has provided a rich range of perspectives in the project.

In creating a collaboration with the right team composition, strategies include providing choices and structuring groupwork opportunities to actively engage all participants, including leaders, presenters, and facilitators with a range of expertise in both science and education, considering the scope of feasibility, targeting activities to identified relevant needs, recognizing faculty members' efforts, and factoring in both action and reflection.

Indeed, many of the initial ACE-Bio Network activities highlighted important differences in perspectives that arise from different stakeholder groups. In a small group with network members outside their own discipline, participants were tasked with explaining key publications and resources that represent valuable examples of work they identify as important within their own subdisciplines. These contributions were summarized and shared at an ACE-Bio Network founders meeting, which led to broader discussions about the scope of the network and processes through which cooperation and collegiality from the broader community would be encouraged and managed. This step was key in establishing the guiding principles for collaboration across disciplinary boundaries summarized in Table 1, in which we outline expectations and responsibilities of all members with regard to work, management of the network, and credit for the products.

\section{Collegial Inclusion Is Grounded in Flexibility and Methods of Collaboration}

An important structural aspect of the ACE-Bio Network is the support for flexibility with regard to participation. For instance, to address distance as a potential obstacle to a successful collaboration, ACE-Bio Network meetings were held in different regions (Indiana, New York, California, and North Carolina). Participants who traveled a distance for one meeting got to attend another one close to home and to help recruit additional participants from their own regions as well as from types of institutions that are not so different from their own. Because the academic calendar varies among institutions, face-to-face meetings have also been scheduled at different times of the year.

To illustrate with an example of methods that inspired curiosity about the challenges and affordances faced by others, consider again the contrasting cases of the biochemistry professor in California teaching about pancreatic cancer research versus the professor working with students doing experimentation at a 2-year college by investigating microbial diversity on Arabia Mountain in Georgia. The distance between their biology disciplines, the distance between their different types of institutions, and even geographic distance could have been obstacles to collegiality. However, with a shared focus on biological experimentation, project members demonstrated curiosity and independence of thought plus mutual respect and flexibility in considering how to find out whether students in each context showed understanding of experimental research (or not). With meetings focused on brainstorming, group problem solving, and network-planning activities designed to result 
in a product, the limited face-to-face time becomes productive in terms of products that will generalize in spite of the separation distances.

Like other network projects, the ACE-Bio Network also relies on asynchronous contributions by deploying technology that allows for broader participation through virtual collaboration. Online tools to connect members and accomplish group work include the following: 1) Dropbox to share literature, syllabi, examples of assessment tools, and reflections; 2) Google Docs to draft and refine collaborative work such as statements of competencies; 3) Mendeley to share and store relevant literature; and 4) Qualtrics for construction of surveys to gather data, ideas, and feedback from participants. In addition to the use of online tools to support professional collaboration, we also put the ACE-Bio Network on ResearchGate.net as a project with monthly updates so that educators in related fields can recognize and contribute to collegial aspects of our project and benefit from the experience of others.

\section{Collegiality Recognizes and Values the Diversity of Professional Identities}

In spite of the care taken in designing the ACE-Bio Network, several challenges associated with the diversity of perspectives of its members had to be addressed to optimize the collegial interaction between members. First, the interdisciplinary nature of the ACE-Bio Network was made explicit when founding members were asked to characterize their professional activities by indicating the percentage of the time over the past 20 years that they have been acting as a scientist versus as an education specialist. These data were intended to help participants recognize their specific areas of competence while identifying their own limitations in areas where other network participants may have more expertise. Although planned as a simple task, the difficulty of separating biology research from biology education research and characterizing activities in one category or the other quickly became apparent, particularly when taking into account professional efforts over the past two decades. Several group members felt the distinction between scientist and education specialist was artificial and difficult to quantify, while others felt it accurately described the division between their professional activities. The group discussed the changing face of scientific research and divergent paths taken by various biology disciplines as potential factors to include when considering the expertise needed for the ACE-Bio Network. The discussion around this activity reinforced the importance of developing agreed-upon norms to maintain the integrity of the network. These are listed under the Consensus heading below and summarized in Table 1. As part of the work of the ACE-Bio Network, the diversity of identities and network members' reactions will continue to be explored, as detailed in the next section, Communication.

In summary, we have identified the principle of collegiality as a key factor in ensuring the success of our collaborative network. We recommend that other networks consider a similar approach by being open about differences and distances that need to be bridged; being explicit about why different stakeholders are present and valued; taking a flexible approach to setting meeting places, times, and formats; and using group methods of collaboration that expose the areas of overlap for convergence toward products aligned with project goals.

\section{COMMUNICATION: USE LANGUAGE CAREFULLY TO GIVE EVERYONE A SENSE OF BELONGING}

Communication can be defined as the process of meaningful interaction among individuals (Table 1 and Figure 1). Communication involves articulation of a message, transmission of information, and the process of interpreting meaning so as to produce understanding. Good information exchange involves feedback. Thus, when collaborating network members communicate through sharing of resources, ideas, difficulties, challenges, mistakes, failures, and feedback with others, they must recognize disciplinary diversity (Table 1 and Figure 1). Concerns about labeling of subdisciplines were apparent when several participants took issue when, perhaps naively, it was assumed they belonged to a particular subdiscipline. For instance, while some members might describe a participant as belonging to "botany" or "plant biology," that biologist might feel his or her work falls more accurately under molecular biology, ecology, evolutionary biology, or physiology. This feedback is important, as labeling can potentially deter some participants from contributing if they feel their contributions and the perspective of a group they actually represent might be mischaracterized. A way to avoid this problem is to make sure that each participant gets ample opportunity to characterize his or her own identity rather than having it assigned by others.

\section{Avoid or Define Jargon}

Our deep and specialized disciplinary knowledge presents many challenges to both scientists and education specialists that need to be acknowledged when we communicate across disciplinary boundaries. Communication is one of the "Five 'C's' of Collaboration" (Figure 1 and Table 1), because words must be carefully chosen and language must be carefully defined to avoid any confusion. Several examples confirm a report by Baker (2015), who wrote that language is one of the problems faced by individuals when they collaborate with those from a different but complementary intellectual discipline. For instance, Bergman and Schooley (2003) reported that education jargon was an obstacle to their collaboration, but it was dealt with by means of a workshop for scientists interested in education. Peffer and Renken (2016) reported on discipline-specific uses of the word "theory" as an example of jargon that poses a barrier to collaborations with both DBER and learning sciences investigators.

We quickly discovered the need to avoid jargon and to carefully select inclusive language when a few scientists and education specialists, steeped in their own disciplinary perspectives, first met to establish the NSF-funded ACE-Bio Network. Initially, this RCN had the name "Assessment of Competence in Experimental Design in Biology." As an early collective action, we elected to change the network name to the "Advancing Competencies in Experimentation-Biology Network" for the following reasons. The term "assessment" was problematic, because scientists, who are dedicated educators actively involved with introducing discovery and experimentation to students, reported not wanting to spend much time on an "assessment" project, as their efforts to develop assessments might not be valued by colleagues in their department. Whereas education specialists are expected by their colleagues to align assessment with curriculum and instruction anytime they think about instructional objectives, the goal for scientists is to share what is most exciting about research. Both groups want to know that their students are 
becoming more competent, so they fit together into the networking process when they consider what students should know from their own disciplinary perspectives. Scientists are valuable collaborators who can detail what a competent scientist does and how that differs from what students do when they are not yet competent to contribute to meaningful discovery. To communicate this value, the term "assessment" was dropped in favor of "advancing" experimentation in biology, something all network members see themselves doing.

\section{Define and Use Inclusive Terms}

Derogatory views associated with language provide another example of the need to carefully select and define terms. For example, Peffer and Renken (2016) provide a detailed discussion of underlying tension due to arrogance and a history of differences between the "hard" and "soft" sciences as a barrier to interdisciplinary integration. We encountered a similar problem in discussions about experiments, which we defined as a scientific procedure to make a discovery or test a hypothesis to support inferences about cause and effect. However, some biology disciplines reserve the term "experiment" for the case when an investigator manipulates the system of study. Others consider that an experiment might be a comparative study, such as an experimental research study that involves comparing similar systems in two different spaces or at two different times. According to Gotelli and Ellison (2004), instead of "nonexperimental" research, a better distinction is "manipulative experiment" versus "observational study." In fact, to avoid a derogatory connotation, the terms "mensurative" and "manipulative" experiments were introduced and defined to clarify different types of systematic work done across a range of scientific investigations.

In summary, we have found that words have different meanings in different areas. To open communication lines early in the process, words must be selected carefully and jargon clearly defined. Good communication and inclusivity of language helped us open doors to interdisciplinary knowledge integration.

\section{CONSENSUS: PROTECT THE COLLABORATIVE AND EQUITABLE DECISION-MAKING PROCESS NEEDED FOR INTERDISCIPLINARY KNOWLEDGE INTEGRATION}

Consensus has two meanings of relevance. One meaning refers to agreement among network members who retain autonomy. The other meaning refers to the practice of getting such agreements. Within a successful collaboration, network members are committed to collective decision making and reaching consensus (Figure 1) on the roles, tasks, and processes for addressing the shared problem. For the purposes of this paper, by "consensus" we mean that there has been serious consideration of every member's opinion and a decision has been made jointly, even if the decision is to accept divergent rather than convergent perspectives (Table 1).

\section{Recognize Areas of Divergence to Achieve Consensus}

Collective decision making across the separation between biology research and biology education or teaching practice must take into account the practical difficulties in creating a common language and the different professional motivations and efforts mentioned earlier. The participants must recognize that progress comes from curiosity and true desire for understanding without denying the knowledge and rationality of the other discipline (see Table 1, "Consensus"). Peffer and Renken (2016) refer to this as making "a concerted effort to understand the disciplinary practices of their collaborators without sacrificing their own perspectives" (p. 8).

Many skills and specifics of training differ across biological subdisciplines and from other science disciplines, making it difficult to synthesize ideas to reach consensus about where to focus training for future scientists. Given the range of different disciplines that are carefully and strategically balanced so that no stakeholder is missing, there is a need to negotiate areas of divergence and to facilitate fair and just knowledge integration. For this reason, the ACE-Bio Network leadership team worked with participants to explicitly outline ethical actions.

\section{Address Ethical Issues}

In line with the overlapping nature of Figure 1, we see sound ethical practice as key to the engagement of all of the "Five ' $\mathrm{C}$ 's' of Collaboration." That said, we raise ethical issues under the consensus principle, because, in our personal experience, ethical issues must clearly be addressed when disciplinary diversity becomes apparent in discussions about areas of consensus and divergence. To mitigate ethical dilemmas, group norms or rules of engagement were agreed upon by ACE-Bio Network founding members to promote collaboration and consensus. According to a review of the literature on collaboration in the sciences, problems with research integrity are among the ethical issues for collaborators to address (Leahey, 2016). Youtie and Bozeman (2014), with a Web-based survey, identified problems related to coauthorship credit to be a major problem. For instance, a contributor who does not receive appropriate credit may feel exploited, or if someone is included as a coauthor without having made a meaningful contribution, research integrity is threatened. Furthermore, there are cultural differences between fields in authorship norms (putting the senior author first or last) or publication norms (conference proceedings hold as much weight as journal articles in some fields). The ACE-Bio Network members reached consensus on the following group norms for ethical decision making as a prerequisite to any action (Anderson, 2005; Hanson, 2014):

1. Be transparent: Be open and describe what is being done so that everyone can see-no hidden agendas.

2. Share decision-making: Find common ground to develop short- and long-term goals and agree on how to document the decision-making processes.

3. Critique the product and not the person: Because all want to find the best outcome, do not take things personally, but share and improve the product.

4. Mutual respect and inclusivity: Be interested in learning from each other and with each other, because when everyone contributes ideas and opinions, each has opportunities to understand a range of voices and can recognize his or her own limitations and gain knowledge from others.

5. Authorship: Give credit and decide up front on authorship and contributions.

6. Professional integrity: Without judgment, be curious and share mistakes, failures, difficulties, and challenges to improve through self-evaluation.

In summary, the ACE-Bio Network established norms to protect multiple stakeholders, to make decisions and set tasks to 
advance the career trajectory of each participant, and before taking an action, to ask if the action is within one's area of competence or if it violates previously agreed-upon rules or codes of ethical practice. Consensus, whether convergent or divergent, proved to be key to the success of our network, and we recommend other networks consider focusing on this principle to enhance collaboration.

\section{CONTINUITY: ESTABLISH MECHANISMS FOR ONGOING LEARNING FROM THE EXPERIENCES OF OTHERS}

For the purposes of this essay, "continuity" is defined as the qualities that do not stop or change as time passes, such as the iterative refinement and unbroken operation of strategies for collaborative work informed by past experiences. An important lesson learned while developing the ACE-Bio Network is that success will ultimately depend on continuity-the ongoing active participation by stakeholders connecting biology research disciplines with biology education. In our experience, meetings, publications, useful education resources, and infrastructure for online sharing can all support continuity of the network. The persistent participation of members from a broad range of subdisciplines and backgrounds is key to ensure that the competencies, assessments, and instructional approaches developed by the network are continually validated for use at many different biology institutions, including for the needs of stakeholders in the broader biology education and research community. Toward this goal, mechanisms must be put in place to ensure both continuity and the monitoring and evaluation of the progress of the ACE-Bio Network.

We have worked to hold annual face-to-face meetings that bring in new people, allow more senior members to mentor and share their experience, and provide a venue for new network members to contribute and share relevant ideas and resources so that no stakeholder is left out. An important challenge, though, is to confirm that new participants are committed to addressing the shared problem and that they also understand why the particular problem requires an ongoing team approach. As long as the targeted problem persists, success also depends on maintaining the disciplinary mix needed to establish appropriate roles for research scientists, educators, and faculty development specialists, who continue to work together with the team composition needed to address the shared problem. The diversity of those who value or contribute to the work of the network adds new utility to the work. To avoid jargon, communication with new members at a meeting can be facilitated by more senior mentors who listen carefully and ask for clarification at every step of activities designed for sharing resources, ideas, difficulties, challenges, mistakes, failures, and feedback. Furthermore, when new members arrive, their voices must be included in collective and ethical decision making and reaching consensus on how collective actions will affect the well-being of others, as well as in setting tasks in accordance with benefits to the career trajectory of each new participant. Thus, the first four principles (Figure 1 and Table 1) are integral to the fifth principle of continuity of a research coordination network that is focused on addressing the shared problem.

A common way to measure successful continuity of a research coordination network is by monitoring research productivity of members over time and to what extent their publications reflect interdisciplinary impact. All this can be monitored through measuring the network's scientific output with citation analysis of publications. The number of times other authors mention the work of a publication or author, reflected in the h-index (Hirsch, 2005), is one such measure of impact, but this may not be the best approach. More multiple-author publications (compared with single-author papers) were reported by Baker (2015) to be evidence of research productivity of interdisciplinary science collaborations. However, for collaborating learning sciences and DBER faculty, Peffer and Renken (2016) noted that the DBER faculty might not normally read journals in which learning sciences faculty report their findings and vice versa. Therefore, the first problem identified is that no single citation-analysis tool collects all publications and their cited references for work that involves investigators from these different disciplines. Second, publication impact measures may not be sufficient to quantify the impact from improvements in undergraduate biology education resources, because citation analysis is a poor measure of classroom use of an educational product; innovative and valuable instructional activities or assessments may be broadly used without being highly cited. For example, the publication about a partnership described by Bergman and Schooley (2003) was cited only once, even though the project resulted in Microscopic Explorations, an educational resource that has been widely used by educators for more than 15 years. Third, published opinions about controversial educational issues or ideas may garner a disproportionate occurrence of citations when they are subsequently refuted or confirmed with research evidence. Finally, the RCN-UBE program provides funds to establish an RCN but not for doing the research that would lead to publication outputs from network members. Thus, citation analysis may not reflect work focused on fine-tuning the quality of network activities. Clearly, alternative indicators of continuity and collaboration are needed to complement publication and citation analysis for evaluating any RCN-UBE project.

Online tools and technology were mentioned previously as holding promise to bridge the gap between the scientists doing cutting-edge research and biology education specialists who are focused on advancing undergraduate education. Visual methods are also emerging as a popular research approach. These and other collaborative methods remain to be explored. For instance, we do not yet know whether or not our use of ResearchGate.net as a home for the ACE-Bio Network can disrupt a tendency to underestimate the value gained when biology educators learn from the experience of others at the cutting edge. From our experiences with the ACE-Bio Network, continuity as we described it has been a key principle in ensuring good collaboration, and therefore success of our network, which suggests that that this principle could be investigated as a factor to advance other networks.

\section{SUMMARY AND IMPLICATIONS}

In this essay, we proposed a community-building framework we created to enhance collaboration within our RCN-UBE ACE-Bio Network that focuses on advancing undergraduate biology students' competence in experimentation. More specifically we proposed the "Five 'C's' of Collaboration" as guiding principles for knowledge integration: commitment, collegiality, communication, consensus, and continuity, and illustrated each principle with examples from the ACE-Bio Network. We also compared 
our framework with features identified in published reports about effective interdisciplinary collaborations focused on biology education (Bergman and Schooley, 2003; Peffer and Renken, 2016). Abundant research reports on collaborations like these have been published, but according to a review of the literature by Leahey (2016), few explanatory models of relevant factors exist to prompt greater rates of collaboration. Thus, we propose a novel framework used by the ACE-Bio Network to advance student competencies in experimentation (as described here) may also be worthy of testing by others who are facing the challenges and need solutions to promote interdisciplinary collaboration. Any meaningful transformation of biology education must include input from all relevant stakeholders, who will share many of the same challenges that our network is facing and addressing. The lessons we learned from the ACE-Bio RCN may prove helpful for other network partnerships that wish to address broad educational challenges in biology. In fact, the "Five 'C's' of Collaboration" might be viewed as a framework that provides areas of focus for evaluating progress and effectiveness of other networks and their engagement across stakeholder groups. The principles could be tested with a range of project evaluation questions like, for example, the following discussion questions:

Commitment: Do project members agree on what the project hopes to accomplish and why?

Collegiality: Do network members operate from a position of mutual respect and does the expertise and team composition include investigators who contribute according to their specific expertise at different career stages, who are from different types of institutions, and who bridge the distance between various regions, cultures, and subdisciplines?

Communication: What has been done to avoid jargon, to select inclusive language, and to address language barriers to knowledge integration?

Consensus: Given the range of different disciplines that are carefully and strategically balanced so that no stakeholder is missing, are (ethical) norms in place to support an equitable process of collective decision making, recognizing divergence, and reaching consensus on roles, tasks, and processes for achieving useful products?

Continuity: How well does the infrastructure for communication and sharing enhance opportunities for ongoing collaboration, network development, and expansion of opportunities to learn from the experience of others?

In conclusion, as demonstrated by the overlapping areas of our framework in Figure 1, this essay reveals interdependence among these five principles. They are not separate elements, but work in concert during network activities. Therefore, we are suggesting that none of these principles should be managed in isolation while neglecting the others. In our view, and based on both a review of the literature and our experience with the ACE-Bio Network, these principles should be considered in an integrated manner for the optimization of network collaborations. Thus, shining a light toward each of these elements might illuminate thoughts on how to make a collaboration work better to foster improvements in undergraduate biology education and positively impact future students. As a starting point for future research and project evaluation designs, we offer the "Five 'C's' of Collaboration" as a framework to test for RCN-UBE projects and other collaborative efforts with potential to effectively meet the goals laid out in national calls to improve biology education (AAAS, 2011) for future generations.

\section{ACKNOWLEDGMENTS}

We gratefully acknowledge all members of the ACE-Bio Network for their wide-ranging contributions to the success of this project. In particular, we thank the research scientists and education specialists who shared ideas collected under IRB protocol \#1506016184 for RCN-UBE: ACE-Bio Network Phase 2. We also thank three scientists, James B. Bassingthwaighte, James D. Forney, and Jeffrey P. Hill, who were willing to share their professional experiences through presentations and discussions with us, to catalyze this report. Additionally, we thank our external advisory board members (Cynthia M. Bauerle, Erin Dolan, Maria Araceli Ruiz-Primo, and James Pellegrino) for their advice and support. This work is supported by NSF grant \#1346567 for the Advancing Competencies in Experimentation-Biology (ACE-Bio) Network. Any opinions, findings, and conclusions or recommendations expressed are those of the authors and do not necessarily reflect the views of the NSF.

\section{REFERENCES}

American Association for the Advancement of Science. (2011). Vision and change in undergraduate biology education: A call to action. Washington, DC.

Anderson, T. R. (2005). The effective practice of agricultural science. In Van Niekerk, A. (Ed.), Ethics in agriculture: An African perspective (pp. 143163). Dordrecht, Netherlands: Springer.

Anderson, W., Banerjee, U., Drennan, C. L., Elgin, S. C. R., Epstein, I. R. Handelsman, J., ... Warner, M. (2011). Changing the culture of science education at research universities. Science, 331, 152-153.

Anderson, T. R., \& Rogan, J. M. (2011). Bridging the educational research-teaching practice gap. Curriculum development, part 1: Components of the curriculum and influences on the process of curriculum design. Biochemistry and Molecular Biology Education, 39(1), 68-76.

Baker, B. (2015). The science of team science: An emerging field delves into the complexities of effective collaboration. BioScience, 65(7), 639-644 https://doi:10.1093/biosci/biv077

Bergman, L., \& Schooley, C. (2003). A successful educational collaboration between scientists and educators: Microscopic Explorations. Cell Biology Education, 2(1), 25-28. https://doi.org/10.1187/cbe.02-03-0005

Boix Mansilla, V., \& Duraisingh, E. D. (2007). Targeted assessment of students interdisciplinary work: An empirically grounded framework proposed. Journal of Higher Education, 78(2), 215-237.

Bush, S. D., Pelaez, N. J., Rudd, J. A., Stevens, M. T., Tanner, K. D., \& Williams K. S. (2006). On hiring science faculty with education specialties for your science (not education) department. Cell Biology Education, 5 , 297-305.

Bush, S. D., Pelaez, N. J., Rudd, J. A., Stevens, M. T., Tanner, K. D., \& Williams K. S. (2008). Science faculty with education specialties. Science, 322, 1795-1796.

Bush, S. D., Pelaez, N. J., Rudd, J. A., Stevens, M. T., Tanner, K. D., \& Williams, K. S. (2011). Investigation of science faculty with education specialties within the largest university system in the United States. CBE-Life Sciences Education, 10(1), 25-42.

Bush, S. D., Pelaez, N. J., Rudd, J. A., Stevens, M. T., Tanner, K. D., \& Williams, K. S. (2013). Widespread distribution and unexpected variation among science faculty with education specialties (SFES) across the United States. Proceedings of the National Academy of Sciences USA, 110(18), $7170-7175$.

Bush, S. D., Pelaez, N. J., Rudd, J. A., Stevens, M. T., Tanner, K. D., \& Williams K. S. (2015). Misalignments: Challenges in cultivating science faculty with education specialties in your department. BioScience, 65(1), 81-89. 
Cheruvelil, K. S., Soranno, P. A., Weathers, K. C., Hanson, P. C., Goring, S. J., Filstrup, C. T., \& Read, E. K. (2014). Creating and maintaining highperforming collaborative research teams: The importance of diversity and interpersonal skills. Frontiers in Ecology and the Environment, 12(1), 31-38.

Cooke, N. J., \& Hilton, M. L., (Eds.). (2015). Enhancing the effectiveness of team science. Washington, DC: National Academies Press.

Dasgupta, A. P., Anderson, T. R., \& Pelaez, N. (2014). Development and validation of a rubric for diagnosing students' experimental design knowledge and difficulties. CBE-Life Sciences Education, 13, 265-284.

D'Avanzo, C., Anderson, C. W., Hartley, L. M., \& Pelaez, N. (2012). A faculty-development model for transforming introductory biology and ecology courses. BioScience, 62(4), 416-427.

Davidson, J. F. (1957). An experimental approach in teaching elementary botany. American Biology Teacher, 19(5), 148-151.

Del Giorno, B. J. (1969). The impact of changing scientific knowledge on science education in the United States since 1850. Science Education, 53, 191-195

Diaz Eaton, C., Allen, D., Anderson, L. J., Bowser, G., Pauley, M. A., Williams, K. S., \& Uno, G. E. (2016). Summit of the research coordination networks for undergraduate biology education. CBE-Life Sciences Education, 15(4), mr1. https://doi.org/10.1187/cbe.16-03-0147

Felder, R. M., Brent, R., \& Prince, M. J. (2011). Engineering instructional development: Programs, best practices, and recommendations. Journal of Engineering Education, 100(1), 1-28.

Gormally, C., Brickman, P., \& Lutz, M. (2012). Developing a Test of Scientific Literacy Skills (TOSLS): Measuring undergraduates' evaluation of scientific information and arguments. CBE-Life Sciences Education, 11(4), 364-377.

Gotelli, N. J., \& Ellison, A. M. (2004). A Primer of ecological statistics. Sunderland, MA: Sinauer.

Hanson, K. (2014). Making an Ethical Decision: A Practical Tool for Thinking through Tough Choices [mobile phone app]. Retrieved March 17, 2018, from https://legacy.scu.edu/ethics/ethical-decision

Hirsch, J. E. (2005). An index to quantify an individual's scientific research output. Proceedings of the National Academy of Sciences USA, 102(46), 16569-16572

Jacob, N. P. (2012). Investigating Arabia Mountain: A molecular approach. Science, 335(6076), 1588-1589.

Leahey, E. (2016). From sole investigator to team scientist: Trends in the practice and study of research collaboration. Annual Review of Sociology, 42, 81-100.

Mason, J. M. (1952). An experimental study in the teaching of scientific thinking in biological science at the college level. Science Education, 36, $270-284$.
National Academies of Sciences, Engineering, and Medicine. (2017). Undergraduate research experiences for STEM students: Successes, challenges, and opportunities. Washington, DC: National Academies Press. https://doi.org/10.17226/24622

Peffer, M., \& Renken, M. (2016). Practical strategies for collaboration across discipline-based education research and the learning sciences. CBE-Life Sciences Education, 15(4), es11. https://doi.org/10.1187/CBE.15-12-0252

Pelaez, N., Anderson, T. R., Gardner, S. M., Yin, Y., Abraham, J. K., Bartlett, E., ... Stevens, M. (2017). The basic competencies of biological experimentation: Concept-skill statements. (Purdue ePubs PIBERG Instructional Innovation Materials, Paper 4). Retrieved March 17, 2018, from https:// docs.lib.purdue.edu/pibergiim/4

Pelaez, N., Anderson, T. R., \& Postlethwait, S. N. (2015). A vision for change in bioscience education: Building on knowledge from the past. BioScience, 65(1), 90-100.

Rogan, J. M., \& Anderson, T. R. (2011). Bridging the educational research-teaching practice gap: Curriculum development, part 2: Becoming an agent of change. Biochemistry and Molecular Biology Education 39(3), 233-241.

Sirum, K., \& Humburg, J. (2011). The Experimental Design Ability Test (EDAT). Bioscene: Journal of College Biology Teaching, 37(1), 8-16.

Spell, R. M., Guinan, J. A., Miller, K. R., \& Beck, C. W. (2014). Redefining authentic research experiences in introductory biology laboratories and barriers to their implementation. CBE-Life Sciences Education, 13(1), 102-110.

Vasaly, H. L., Herrera, J., Sullivan, C. H., \& Denniston, K. J. (2013). News from the funding front: Upcoming opportunities, proposals welcomed. CBELife Sciences Education, 12(1), 1-4. https://doi.org/10.1187/cbe.12-12 $-0213$

Wlodkowski, R. J. (1999). Enhancing adult motivation to learn: A guide to improving instruction and increasing learner achievement (rev. ed.). San Francisco: Jossey-Bass.

Woodhull, J. F. (1918). The teaching of science. New York: Macmillan.

Woodin, T., Carter, V. C., \& Fletcher, L. (2010). Vision and Change in Biology Undergraduate Education, A Call for Action-initial responses. CBE-Life Sciences Education, 9(2), 71-73. https://doi.org/10.1187/cbe.10-03 $-0044$

Woodin, T., Feser, J., \& Herrera, J. (2012). The vision is set, now help chronicle the change. CBE-Life Sciences Education, 11, 347-350. doi: 10.1187/ cbe.12-09-0162

Youtie, J., \& Bozeman, B. (2014). Social dynamics of research collaboration: Norms, practices, and ethical issues in determining co-authorship rights. Scientometrics, 101, 953-962. 